\title{
La empresa que genera valor añadido compartido
}

\section{Pilar Tirado Valencia' y Mercedes Ruiz Lozano²}

Palabras clave: desarrollo sostenible, responsabilidad social empresarial, valor añadido.

Key words: sustainable development, corporate social responsibility, value added.

Mots clés: développement durable, responsabilité sociale des entreprises, valeur ajoutée.

La crisis de la economía mundial, junto con el crecimiento de la población sacudida en su mayoría por la pobreza y las desigualdades, así como la degradación del medio ambiente, son problemas de tal magnitud que evidencian la necesidad con carácter urgente de un cambio hacía un nuevo modelo de crecimiento económico más sostenible. La sostenibilidad es una de las cuestiones que con más frecuencia se plantean hoy en día en los debates de los organismos internacionales sobre desarrollo económico, en las Cumbres de la Tierra o sobre el Cambio Climático, como consecuencia de la presión de la sociedad civil, convirtiéndose en una variable clave para la competitividad de las empresas.

Algunos datos sobre las graves consecuencias del modelo económico actual no pueden dejarnos indiferentes. Un alto porcentaje de la población mundial vive por debajo del umbral de la pobreza. Tan sólo una cuarta parte de la población habita en países industrializados en los que se consumen un $80 \%$ de los recursos naturales. Para atender las necesidades básica del $75 \%$ de la población mundial,

\footnotetext{
' Departamento de Finanzas y Contabilidad. Universidad Loyola Andalucía.

${ }^{2}$ Departamento de Finanzas y Contabilidad. Universidad Loyola Andalucía.
} 
será necesario un crecimiento significativo de la actividad económica en los próximos 50 años, que incrementará aún más el consumo de energía y la degradación medioambiental. Sin embargo, la capacidad productiva de los recursos del planeta se encuentra al límite de sus posibilidades.

El modelo de crecimiento económico actual ha desembocado en el consumo sin restricciones de los recursos naturales por parte de las empresas. La actividad empresarial, especialmente la de las grandes multinacionales, desencadena un amplio abanico de efectos perjudiciales sobre el medio ambiente, y es la principal causante de importantes deterioros ecológicos. Por ello, las empresas deben asumir un papel protagonista en el "cuidado de la casa común". Para así contribuir al "desarrollo sostenible" de acuerdo con la definición del informe Brundtland (1987), "un desarrollo que satisface las necesidades presentes sin comprometer la habilidad de las generaciones futuras para satisfacer las suyas", buscando el equilibrio en la atención de tres dimensiones básicas: el desarrollo económico, la protección del medio ambiente y la equidad social. Porque

sólo puede considerarse ético un comportamiento en el cual los costes económicos y sociales del consumo de recursos se reconozcan de manera transparente y sean sufragados por aquellos que se benefician (LS 195).

La Responsabilidad Social de la Empresa (RSE) surge para regular el rol que las empresas juegan en su contribución a ese desarrollo sostenible, dando respuesta a las expectativas de sus grupos de interés. Para algunos autores la RSE es el resultado de la aplicación de la ética en los negocios. Para otros, se trata de la adaptación del concepto de sostenibilidad al mundo de las organizaciones, por lo que se trata de analizar el desempeño de las empresas en el ámbito de sus tres dimensiones, abordando las cuestiones sociales y medioambientales, sin despreciar los resultados económicos que garanticen la viabilidad y la supervivencia de la empresa, lo que se conoce como la denominada Triple Cuenta de Resultados (Elkington, 1997). A estas tres dimensiones se añaden hoy en día también las relativas al buen gobierno, la transparencia, los mecanismos anticorrupción o la gestión de riesgos reputacionales, entre otras.

Llegados a este punto, tal vez sea el momento de definir qué se entiende por Responsabilidad Social de la Empresa. Una de las definiciones sobre el concepto de RSE más comúnmente aceptada y completa es la que nos proporciona la UE (2011):

Para asumir plenamente su responsabilidad social, las empresas deben aplicar, en estrecha colaboración con las partes interesadas, un proceso destinado a integrar las preocupaciones sociales, medioambientales y éticas, el respeto de los derechos humanos y las preocupaciones de los consumidores en sus operaciones empresariales y su estrategia básica, a fin de: 
- Maximizar la creación de valor compartido para sus propietarios/accionistas y para las demás partes interesadas y la sociedad en sentido amplio;

- identificar, prevenir y atenuar sus posibles consecuencias adversas.

Al contemplar la necesidad de generar un valor añadido compartido con todos sus grupos de interés, se está reconociendo la importancia de atender las demandas de una amplia diversidad de stakeholders que no son indiferentes a la actividad empresarial. A la responsabilidad por satisfacer los intereses de los inversores, se suman ahora las preocupaciones de los empleados, clientes, administraciones públicas, proveedores, comunidad local, e incluso de la sociedad en general; pero además de forma transversal, es decir, en todos los ámbitos de la gestión empresarial. Así asume la empresa su corresponsabilidad para atender los grandes retos económicos, sociales y medioambientales que tiene hoy el mundo.

Independientemente de las muchas definiciones que existen acerca de la RSE, para nosotras se trata de un concepto impreciso, elástico y maleable. Impreciso porque lo social es intangible, es subjetivo y está sujeto a distintas interpretaciones, por lo que el término RSE resulta confuso. Además es difícil de delimitar, dada la diversidad de manifestaciones que la RSE presenta y que incluye ámbitos como el del respeto a los derechos humanos, la conciliación de la vida personal y profesional, los códigos de conducta, el consumo responsable, el voluntariado corporativo, los planes de igualdad, el comercio justo, las etiquetas ecológicas o el apoyo a causas sociales, por mencionar algunos.

Es un concepto elástico porque abarca un amplio abanico de cuestiones transversales que afecta a todos los ámbitos de la gestión empresarial y de la toma de decisiones, en donde todas las áreas funcionales deben verse implicadas. La fijación de los objetivos estratégicos, las políticas de comunicación y de transparencia, la rendición de cuentas, la evaluación de riesgos, los mecanismos anticorrupción, son sólo algunos de estos aspectos. Tan elástica es la RSE que incluso traspasa las fronteras de la propia organización, y se "estira" hasta introducirse en la cadena de suministros afectando también a la responsabilidad de los proveedores.

Finalmente, se trata de un concepto maleable que evoluciona con el tiempo, ya que va incorporando las preocupaciones que se derivan de los cambios y de los nuevos problemas que surgen en nuestra sociedad. Inicialmente, la preocupación por el medio ambiente fue la que concentró el interés de los organismos internacionales y de la sociedad civil, movilizando importantes campañas de denuncia. Actualmente, los escándalos protagonizados por algunas empresas y los casos de corrupción, están acaparando la mayor atención (uno de los más recientes el de 
la empresa Volkswagen que manipulaba el software que controlaba la emisión de gases contaminantes de sus motores).

Finalmente, la RSE no está exenta ni de debates, ni de polémicas, ni de desafíos.

Entre los debates surgidos, la cuestión sobre la voluntariedad u obligatoriedad de la RSE sigue sin estar resuelta. Aunque algunos países han llegado a regular algunas obligaciones, como la de emitir informes de gobierno corporativo o incluso memorias de sostenibilidad, la amplitud del tema desborda las pretensiones de quienes estiman necesaria la intervención del legislador. Podríamos cuestionarnos si se trata de una obligación legal o moral, y hasta qué punto no es la ética de las personas que dirigen la empresa, y no las leyes, las que dictaminan cuáles son los compromisos de una empresa socialmente responsable con sus grupos de interés.

Otro debate candente es el relativo a la posible injerencia en el libre mercado de las políticas públicas de fomento de la RSE. La cuestión de la adjudicación de las compras y de los contratos públicos a empresas que lideren determinadas políticas de RSE o cumplan determinados requisitos, no han dejado de estar presentes, a la vez, entre las acusaciones y las reivindicaciones de algunas asociaciones empresariales. En este sentido, no debemos olvidar que el papel del marco político e institucional debe ir más allá de evitar malas prácticas, animando y fomentando la adopción de las mejores prácticas (LS 177)

Si nos referimos a las polémicas que se suscitan, la ciudadanía no deja de preguntarse hasta qué punto la RSE es fruto del convencimiento o si detrás se esconde el oportunismo de aquellas empresas que utilizan la RSE como una simple operación de "maquillaje" para tratar de mejorar su imagen y conseguir con ello incrementar las ventas. Que la RSE aporta legitimidad y reputación a las empresas es algo indiscutible $y$, a nuestro juicio, lícito. Sin embargo, cuando de ella se hace un uso estrictamente con fines comerciales, genera desconfianza entre los consumidores, que perciben la falta de coherencia que ello supone. Acontecimientos desgraciados como los sucesos del año 2104 en Bangladesh, en los que se vieron salpicadas las grandes empresas textiles que más abogaban en nuestro país por la RSE, llevan a algunos a tener que ser, cuanto menos, bastante escépticos.

Por último, en cuanto a los desafíos, a nuestro juicio aún hay mucho camino por recorrer en el ámbito de la Responsabilidad Social de la Empresa. Uno de los primeros desafíos es la educación para la sostenibilidad, sólo así se animará la participación y demanda de los grupos de interés, y una actitud crítica que facilite su desarrollo. Otro de los desafíos es la integración de una visión de largo plazo 
en el desarrollo económico, porque es la única manera de comprender que "los esfuerzos para un uso sostenible de los recursos naturales no son un gasto inútil, sino una inversión que podrá ofrecer otros beneficios a medio plazo" (LS 191). Así mismo esa nueva forma de hacer negocios de manera responsable debe ser transparente y comparable, para ello han surgido numerosas iniciativas que han tratado de homogenizar y sistematizar la gestión de la RSE (entre las que podemos destacar el Pacto Mundial de las Naciones Unidas, la Global Reporting Initiative - la Accountability 1000), sin embargo, la estandarización y la interiorización de la RSE en todos los procesos de la gestión empresarial están aún pendientes de alcanzarse plenamente.

\section{Bibliografía}

Elkington, J. (1997) Cannibals with Forks: The Triple Bottom Line of 21 st Century Business, John Wiley.

UE (201 1) Estrategia renovada de la UE para 201 1-2014 sobre la responsabilidad social de las empresas. Disponible en: http://eur-lex.europa.eu/legal-content/ EN/TXT/? uri=CELEX:52011 1DC0681. 